\title{
Optimisation of chemical composition of high-strength structural steels for achieving mechanical property requirements
}

\author{
Oleksandr Babachenko, Hanna Kononenko, Iryna Snigura and Nataliya Togobytska \\ Oleksandr Babachenko. Z.I. Nekrasov Iron and Steel Institute of NAS, Ukraine \\ Hanna Kononenko. Z.I. Nekrasov Iron and Steel Institute of NAS, Ukraine \\ Iryna Snigura. Z.I. Nekrasov Iron and Steel Institute of NAS, Ukraine \\ Nataliya Togobytska. University of Applied Sciences Berlin (HTW), Germany. Corresponding author: Togobytska, Nataliya. E-mail \\ address: Nataliya.Togobytska@htw-berlin.de
}

\begin{abstract}
In addition to thermomechanical treatment, one of the main factors affecting the mechanical properties of steel is the chemical composition. The chemical composition may vary for a special high-strength low-alloy steel to meet certain mechanical property requirements. This work presents an approach, based on the method of physical-chemical modelling developed at the Z.I. Nekrasov Iron and Steel Institute of the National Academy of Sciences of Ukraine, to optimise the chemical composition of high-strength structural steels. The principle of this method is to describe the chemical composition of a melt by a complex of integral model parameters of interatomic interaction, characterising the chemical and structural state of the melt. The experimental data were analysed to obtain the regression model for mechanical properties based on the parameters of interatomic interaction. Finally, a multi-criteria optimisation method was applied to obtain an optimal set of microalloying elements which ensure the required mechanical properties.
\end{abstract}

Keywords. Structural Steels, Mechanical Properties, Chemical Composition, Parameters Of Interatomic Interaction, Modelling, Optimisation

\section{Introduction}

Structural steels are the most commonly used materials in almost all industries worldwide. They are used, for instance, in long- span structures, towers, high-rise buildings, bridges, heavy-duty plants, portal frames and sports stadiums and complexes. Compared to ordinary steel grades, structural steels exhibit increased resistance to atmospheric corrosion and improved mechanical properties, which allows them to occupy a leading position in the metallurgical industry.

Industrial success in the production of high-quality steels is not possible without a scientific foundation, which is provided by advanced research centres through scientific multi-partner projects with the participation of representatives from different countries [1]. In [1] the authors emphasised the key influence of the chemical composition of steels: the metallurgical design of high-strength structural steels is based on the decrease in C content, increase in $\mathrm{Mn}$, introduction of $\mathrm{Al}$ and $\mathrm{Nb}$ for grain refinement and $\mathrm{V}$ for precipitation hardening, and the decrease in $\mathrm{S}$ to improve toughness in the through thickness direction.

The influence of alloying and microalloying on the mechanical properties of high-strength steels has been investigated in many scientific works. In [2] the researchers reported that the higher manganese content resulted in higher hardenability, caused by a austenite to ferrite transformation at a lower temperature, and in finer microstructure in high-titanium microalloyed steels. The effects of the microalloying elements $\mathrm{Nb}, \mathrm{V}$ and $\mathrm{Ti}$ on the microstructure and properties of quenched and tempered steel were studied in [3]. In [4] the authors presented the optimisation of composition ranges for the basic alloying elements to produce an alloy of the Fe-Mn-Al-C system for use in structural applications. Another important aspect is the reduction of steel manufacturing costs while guaranteeing the required quality in production. In [5] the author proposed alloying low-carbon structural steels with a system of carbonitrideforming elements - $\mathrm{Al}(0.02-0.06 \%)+\mathrm{Ti}(0.015-0.030 \%)+\mathrm{N}(0.010-0.025 \%)$ - in order to replace the expensive 
Optimisation of chemical composition of high-strength structural steels for achieving m...

alloying elements $(\mathrm{Al}+\mathrm{V}, \mathrm{Cr}$ or $\mathrm{Ni}+\mathrm{N})$; this made it possible to reduce the cost of production and improve the mechanical properties of several structural steels.

Nevertheless, despite the extensive research into the processes of microalloying, alloying and modification of structural steels, there is no universally accepted technological scheme for customising structural steels to the individual requirements of the customer since raw materials and technological equipment are specific to each production plant.

This work presents an approach, based on the method of physical-chemical modelling developed at the Z.I. Nekrasov Iron and Steel Institute of the National Academy of Sciences (IsI NAS) of Ukraine, for describing the influence of the chemical composition of high-strength structural steels on their mechanical properties. This method relies on the 'folding' of the chemical composition of a melt to a complex of integral model parameters of interatomic interaction, characterising the chemical and structural state of the melt. The novelty of this approach is that through the dimension reduction of the parameter space (chemical composition) to a few integral parameters of the interatomic interaction, even the influence of new microalloying elements on the mechanical properties of steel can be reliably estimated in advance. This type of modelling allows steel producers to significantly reduce the experimental design costs [6].

The parameters of interatomic interaction in melts and solutions at all stages of the production process are very informative. They characterise the charge and structural states of multicomponent steels as chemically uniform systems that are highly sensitive to the addition of alloying and microalloying elements. In this study, a forecast model for mechanical properties, which incorporates the parameters of interatomic interaction, was derived based on an industrial data set. The modelling procedure is described in the third section.

Since there is generally an inverse relationship between the strength and the plastic properties of high-strength steels, an important task is to find a compromise setting of the chemical composition that ensures the stabilisation of the mechanical properties at the required level. This problem can be formulated as a multi-criteria optimisation problem.

In engineering, many different approaches have been developed to solve multiple criteria problems. One of the widely used methods is the desirability function approach proposed by Harrington [7] and later extended by Derringer and Suich [8]. While this method is applicable to a large variety of problems, it is mostly used to optimise the quality of a product. The application of this method and the analysis of the microalloying effects are presented in the fourth section.

\section{Mechanical properties of high-strength structural steels}

Structural steels have a high strength-to-weight ratio that makes them excellent for use in the construction of large structures, such as buildings, warehouses, bridges and factories. They include many standard and proprietary grades designed to provide specific combinations of properties such as strength, toughness, formability, weldability and atmospheric corrosion resistance. In most cases, the current standards for structural steels give mainly the basic requirements, such as limits on chemical composition and tensile properties.

High-strength low-alloy steels belong to a special category of structural steel materials. These steels have greater hardenability than structural carbon steels and can thus provide high strength and good toughness in thicker sections by heat treatment. They have a manganese content of up to $2.0 \%$. Small portions of other alloying elements, such as chromium, nickel, molybdenum, nitrogen, vanadium, niobium and titanium can be used in different combinations to provide improved heat and corrosion resistance. However, as the alloy content increases, the alloy steels become more expensive and more difficult to weld [9].

In terms of mechanical properties, heat-treated (quenched and tempered) low-alloy steels offer the best combination of strength and toughness. Thermomechanical rolling can produce steel plates with a yield strength of up to $500 \mathrm{MPa}$ 
and for special elements even of up to $690 \mathrm{MPa}[10]$.

In this work, an industrial data set was analysed. The data set included heat treatment parameters (cooling rate) and chemical compositions for 400 structural steel plates (12 different steel grades). Table 1 lists the chemical composition and the required mechanical properties of some steels from the data set.

Table 1. Chemical composition and required mechanical properties of structural steels [11] selected from the data set.

\begin{tabular}{|c|c|c|c|c|c|c|c|c|c|c|c|c|c|c|c|}
\hline \multirow{2}{*}{$\begin{array}{l}\text { Steel } \\
\text { grade }\end{array}$} & \multirow{2}{*}{$\begin{array}{c}\text { Equivalents } \\
\text { (exact or closest) }\end{array}$} & \multicolumn{11}{|c|}{ Chemical composition*, \% } & \multicolumn{3}{|c|}{$\begin{array}{c}\text { Mechanical } \\
\text { properties }\end{array}$} \\
\hline & & C & Si & $\mathrm{Mn}$ & $\mathrm{Cr}$ & $\mathrm{Ni}$ & $\mathrm{v}$ & $\mathrm{Cu}$ & $\mathrm{P}$ & s & As & $\mathrm{N}$ & $\begin{array}{c}\sigma_{\mathrm{b}} \\
\mathrm{MPa}\end{array}$ & $\begin{array}{l}\sigma_{0,2}, \\
\mathrm{MPa}\end{array}$ & $\begin{array}{l}\delta_{6}, \\
\%\end{array}$ \\
\hline $14 Г 2 \mathrm{~A} \Phi$ & $\begin{array}{c}15 \mathrm{MnVN} \text { (China) } \\
13220 \text { (Czech) }\end{array}$ & $\begin{array}{l}0,12- \\
0,18 \\
\end{array}$ & $\begin{array}{r}0,3- \\
0,6 \\
\end{array}$ & $\begin{array}{l}1,2- \\
1,6\end{array}$ & $\leq 0,4$ & $\leq 0,3$ & $\begin{array}{l}0,07- \\
0,12\end{array}$ & $\leq 0,30$ & $\leq 0,035$ & $\leq 0,040$ & $\leq 0,08$ & $\begin{array}{l}0,015- \\
0,025\end{array}$ & 540 & 390 & 20 \\
\hline $09 \Gamma 2 \mathrm{C}$ & $\begin{array}{l}\text { 13Mn6, 9MnSi5 } \\
\text { (Germany); } \\
\text { SB49 (Japan); } \\
\text { 12Mn (China) }\end{array}$ & $\leq 0,12$ & $\begin{array}{l}0,5- \\
0,8\end{array}$ & $\begin{array}{l}1,3- \\
1,7\end{array}$ & $\leq 0,3$ & $\leq 0,3$ & - & $\leq 0,3$ & $\leq 0,035$ & $\leq 0,040$ & $\leq 0,08$ & $\leq 0,008$ & $\begin{array}{l}430- \\
490\end{array}$ & $\begin{array}{l}325- \\
365\end{array}$ & $\begin{array}{l}19 . \\
21\end{array}$ \\
\hline 10хснд & $\begin{array}{l}\text { 10ChSND } \\
\text { (Bulgaria) }\end{array}$ & $\leq 0,12$ & $\begin{array}{l}0,8- \\
1,1\end{array}$ & $\begin{array}{l}0,5- \\
0,8 \\
\end{array}$ & $\begin{array}{c}0,6- \\
0,9\end{array}$ & $\begin{array}{l}0,5- \\
0,8 \\
\end{array}$ & - & $\begin{array}{l}0,4- \\
0,6\end{array}$ & $\leq 0,035$ & $\leq 0,040$ & $\leq 0,08$ & $\leq 0,008$ & 530 & 390 & 19 \\
\hline
\end{tabular}

\section{Modelling the influence of chemical composition on mechanical properties}

\subsection{Physical-chemical modelling based on parameters of interatomic interaction in a melt}

To assess the influence of the chemical composition of structural steels on their mechanical properties, a method of physical and chemical modelling developed at the IsI NAS of Ukraine has been used. It describes the chemical composition of a melt by a complex of integrated model parameters of interatomic interaction, characterising the chemical and structural state of the melt. The implementation of this methodology included the following steps [8], [12], [13]:

1. Since phase transformations in steel are a consequence of interatomic interactions in a multicomponent melt, the dimension reduction of parameter space was carried out first. The chemical composition was 'folded' by using the model parameters of the interatomic interaction for a given chemical composition, namely the charge $\mathrm{Z}^{\mathrm{Y}}$ (e) state and the structural $\mathrm{d}\left(10^{-1} \mathrm{~nm}\right)$ state. These parameters result from a pairwise interaction of all $(\mathrm{m})$ components and can be obtained by solving a system of nonlinear $\left(\mathrm{m}^{2}-\mathrm{m}+1\right)$ equations:

$$
\left\{\begin{array}{l}
a-f\left(\Delta e_{i j}^{\prime}\right)=0, \\
d-f\left(\Delta e_{i j}^{-}\right)=0, \quad i=1,2, \ldots, m-1, j=i+1, \ldots, m, \\
4 Z^{X}\left(a, \Delta e^{\prime}\right)+Z^{Y}\left(d, \Delta e^{\prime}\right)=0,
\end{array}\right.
$$

where $\Delta \mathrm{e}_{\mathrm{ij}}$ ' is the number of electrons that are localised when interacting in the direction of the bond $\mathrm{i}-\mathrm{j}$ at a distance a (along the diagonal of the bcc or fcc lattices), $\Delta \mathrm{e}_{\mathrm{ij}}$ " at a distance $\mathrm{d}=0,866$.a along the face, calculated as:

$$
\Delta e^{\prime}=\left(\Delta e_{12}^{\prime}, \Delta e_{13}^{\prime}, ., \Delta e_{i j}^{\prime}, . ., \Delta e_{m-1, m}^{\prime}\right), \quad \Delta e^{\prime}=\left(\Delta e_{12}^{\prime}, \Delta e_{13}^{\prime}, ., \Delta e_{i j}^{\prime}, . ., \Delta e_{m-1, m}^{\prime}\right)
$$

Solving (1) gives: 
Optimisation of chemical composition of high-strength structural steels for achieving m...

$$
a, \Delta e_{i j}^{\prime}, \Delta e_{i j}^{\prime \prime}, i=1, \ldots, m-1, j=i+1, \ldots, m \text {. }
$$

The parameter $\mathrm{Z}^{\mathrm{Y}}$ is determined by averaging the effective charges of all types of bonds $\mathrm{i}-\mathrm{j}$ with the bond length $\mathrm{d}$ :

$$
Z^{Y}=\sum_{k=1}^{m} \frac{\lg R u_{k}^{o}-\lg (d / 2)}{\operatorname{tg} \alpha_{k}} \cdot n_{k}^{2}+2 \cdot \sum_{k=1}^{m-1} \sum_{=k+1}^{m} n_{k} \cdot n_{l} \cdot \Delta e_{k l}^{\prime \prime}
$$

with $\mathrm{n}_{\mathrm{k}}$ being the mole fraction, $\mathrm{Ru}_{\mathrm{k}}{ }^{0}$ the radius of an unpolarised atom, and $\operatorname{tg} \alpha_{\mathrm{k}}$ a parameter that characterises the change in the electron density upon ionisation of the atom of the kth component.

The structural and charge states of interatomic interactions in steels allow one to choose the region with the mechanical properties best suited to a particular consumer demand, taking into account the ratio of, for example, $\mathrm{Z}^{\mathrm{Y}}$ to $\mathrm{d}$. The stronger the interatomic interaction in the metal melt $\mathrm{Z}^{\mathrm{Y}}$ and the smaller the values of the internuclear distance $d$, the higher the strength characteristics of steel (Fig. 1(a)). The strength characteristics of steels decrease from the upper left to the lower right in Fig. 1(a). The choice of an effective composition of microalloying elements can be determined by their influence on the structural state parameter $d_{m l}$. Fig. 1(b) illustrates the qualitative influence of chemical elements on the structural state parameter $\mathrm{d}_{\mathrm{ml}}$ for microalloying elements from the data set normalised to values between 0 and 1.

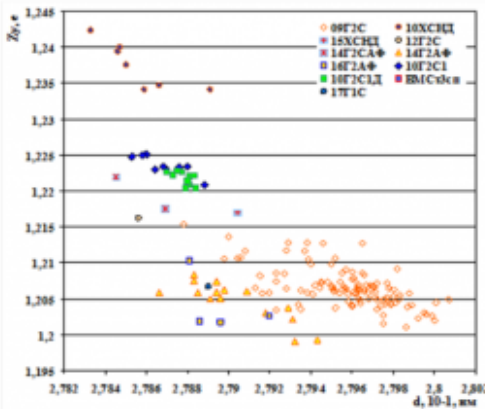

b)

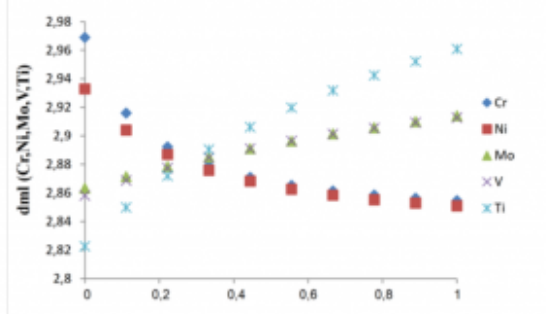

Fig. 1. a) Structural and charge state diagram for structural steels from the experimental data set; the strength characteristics of steels decrease from the upper left to the lower right. (b) The influence of chemical elements on the parameter of structural state $\mathrm{d}_{\mathrm{ml}}$ calculated at the IsI NAS.

1. The next step included the construction of the forecast models for basic mechanical characteristics, such as tensile strength, yield strength and elongation-at-break (denoted by $\sigma_{\mathrm{B}}, \sigma_{0,2}$ and $\delta_{5}$, respectively), as functions of integral model parameters $\left(\mathrm{Z}^{\mathrm{Y}}\right.$ and $\left.\mathrm{d} \mathrm{ml}\right)$ and their combinations based on the experimental data.

2. In step three, the recommended ranges for the integral parameters providing the required level of mechanical properties were determined.

3. The last step involved determining the chemical composition of steel that meets the required ranges of 
integral parameters.

\subsection{Analysis of the model}

A regression analysis was performed to determine how the chemical composition, on the one hand, and the cooling rate, on the other, affect the mechanical properties of steel. For this purpose, the information about the chemical composition, tensile and yield strength, and elongation-at-break for 12 different steel grades from the industrial data set was used. This data set was additionally expanded with parameters $Z^{Y}$ and $d_{m l}$ calculated using (1) for each steel sample.

It is well known that the heat treatment technology has a decisive influence on the final mechanical properties of metal products. The evaluation of the experimental data demonstrated that when the chemical composition of steel remains constant, the tensile strength $\sigma_{\mathrm{B}}$ can be significantly increased by increasing the cooling rate (for example, steels $09 Г 2 \mathrm{C}$ and 10XСНД). As can be seen in Fig. 2, there is a nonlinear relationship between the two variables.

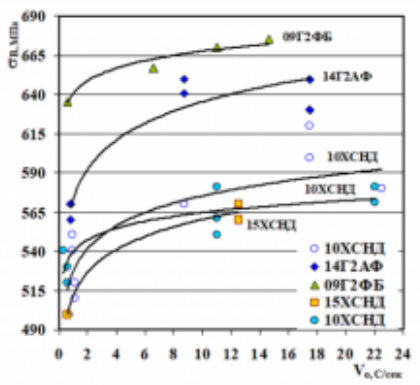

Fig. 2. Effect of cooling rate on tensile strength $\sigma_{\mathrm{B}}$.

It should be noted that the cooling rate as a process parameter depends on the cooling conditions, initial temperature and its distribution, heat transfer coefficient, geometry of the steel product (profile and size) and thermo-physical properties of steel (such as heat capacity and thermal conductivity). In large sheet rolled products, differences in cooling rates over the cross-section of a sheet can result in inhomogeneous microstructure and anisotropic mechanical properties [14].

The particular importance of the cooling rate was also emphasised in [9], [15]. According to [14], a low cooling rate of $0.7^{\circ} \mathrm{C} / \mathrm{s}$ leads to a mixed microstructure consisting of pearlite, ferrite and bainite, whereas a cooling rate increased to $7.5^{\circ} \mathrm{C} / \mathrm{s}$ leads to the formation of martensite and ferrite, which results in the increase in ultimate tensile strength.

The further focus of this work was on the chemical composition and its influence on the mechanical properties of steel. The estimated regression models for the mechanical properties were the following:

$\sigma_{\mathrm{B}}, \mathrm{MPa}=43757+1126 \cdot \mathrm{Z}^{\mathrm{Y}}-31073 \cdot \mathrm{d}_{\mathrm{ml}}+5407 \cdot \mathrm{d}_{\mathrm{ml}}^{2}$, (Multiple $R^{2}=0.72$, Adjusted $R^{2}=0.72$ ),

$\sigma_{0.2}, \mathrm{MPa}=60448+1856 \cdot \mathrm{Z}^{\mathrm{Y}}-43451 \cdot \mathrm{d}_{\mathrm{ml}}+7566 \cdot \mathrm{d}_{\mathrm{ml}}^{2},\left(\right.$ Multiple $R^{2}=0.78$, Adjusted $R^{2}=0.77$ ) 
Optimisation of chemical composition of high-strength structural steels for achieving m...

$\delta_{5}, \%=-3554.54+48.26 \cdot \mathrm{Z}^{\mathrm{Y}}+2434.84 \cdot \mathrm{d}_{\mathrm{ml}}-420.24 \cdot \mathrm{d}_{\mathrm{ml}}^{2},\left(\right.$ Multiple $R^{2}=0.6$, Adjusted $\left.R^{2}=0.57\right)$

After the fitting of the models, an optimisation procedure was performed to obtain the appropriate chemical composition resulting in the desired mechanical properties of structural steel.

\section{Optimisation for mechanical properties}

The problem of determining the appropriate chemical composition for obtaining the mechanical properties within the desired ranges (for instance, $\sigma_{\mathrm{B}} \geq 600 \mathrm{MPa}, \delta_{5} \geq 25 \%$ ) can be formulated as a multiple criteria optimisation problem. In order to solve this problem, the desirability functions approach of Derringer and Suich [8] was applied. The idea behind this method is that for each response variable $Y_{i}$, a desirability function $d_{i}\left(Y_{i}\right)$ assigns numbers between 0 and 1 to the possible values of $Y_{i}$, with $d_{i}\left(Y_{i}\right)=0$ representing a completely undesirable value of $Y_{i}$ and $d_{i}\left(Y_{i}\right)=1$ representing a completely desirable or ideal response value. The individual desirabilities are then combined using the geometric mean, which gives the overall desirability

$$
D=\left(d_{1}\left(Y_{1}\right) \cdot d_{2}\left(Y_{2}\right) \cdot \ldots \cdot d_{k}\left(Y_{k}\right)\right)^{1 / k}
$$

with $\mathrm{k}$ denoting the number of responses. Next, the maximum of the function D defined by (5) has to be calculated. In this work, particle swarm optimisation was implemented in Python to provide the numerical solution for this optimisation problem.

By setting the respse variables as $\sigma_{\mathrm{B}}$ and $\delta_{5}$, described by (2) and (4), with the desired values of $\sigma_{\mathrm{B}} \geq 500 \mathrm{MPa}$ and $\delta_{5}$ $\geq 20 \%$, the solution for the optimisation problem was calculated as $\left(\mathrm{Z}^{\mathrm{Y}^{*}}, \mathrm{~d}^{*} \mathrm{ml}\right)=(1.24,2.82)$. The corresponding values of tensile strength and elongation were ${\sigma_{\mathrm{B}}}^{*}=530 \mathrm{MPa}$ and $\delta_{5}{ }^{*}=29 \%$, respectively. The increase in strength to $\sigma_{\mathrm{B}} \geq$ $600 \mathrm{MPa}$ provides an optimal set of parameters $\left(\mathrm{Z}^{\mathrm{Y}^{*}}, \mathrm{~d}^{*} \mathrm{ml}\right)=(1.22,3.03), \sigma_{\mathrm{B}}{ }^{*}=628 \mathrm{MPa}$ and $\delta_{5}{ }^{*}=24 \%$. For instance, the steels from the experimental data set that met this criteria are 14Г2АФ and 10ХСНД.

As can be seen for mechanical properties, the solution for the formulated multiple criteria optimisation problem is not unique. This is also confirmed by the contour plots for response variables $\sigma_{\mathrm{B}}$ and $\delta_{5}$ presented in Fig. 3 . The combination of high tensile strength over $600 \mathrm{MPa}$ and elongation higher than $25 \%$ can be achieved in the green region of the contour plot for $\sigma_{\mathrm{B}}$ (Fig.4).
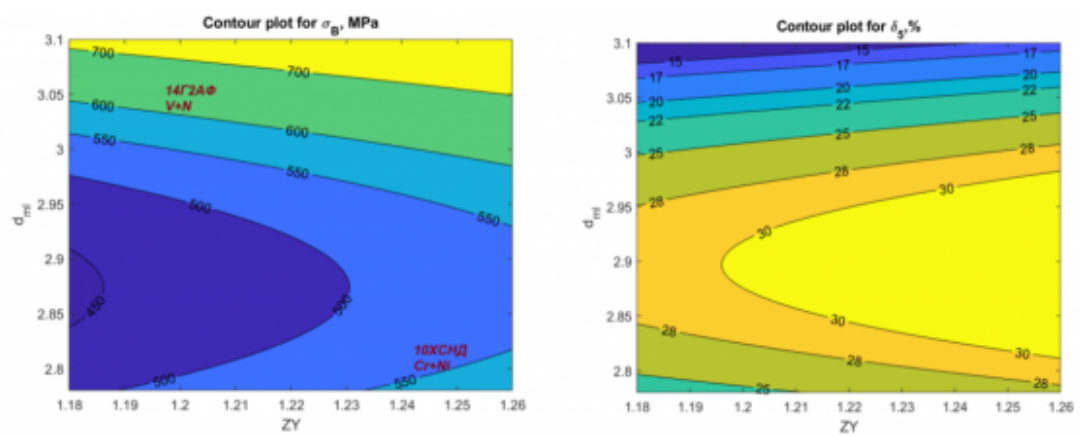
Fig. 3. Contour plots for the tensile strength $\sigma_{\mathrm{B}}$ and elongation-to-break $\delta_{5}$ calculated according to (2), (4).

Different alloying ements can affect the parameters $\mathrm{Z}^{\mathrm{Y}}$ and $\mathrm{d}_{\mathrm{ml}}$ in different ways. For instance, for the steel 10XСНД, alloying with chromium at the level of 0.70-0.75\% increases the charge state of the melt $\mathrm{Z}^{\mathrm{Y}}$ and decreases the structural state $\mathrm{d}_{\mathrm{ml}}$ (Fig. 1 (b)) by strengthening the melt matrix. Consequently, it provides significantly better strength indicators (Fig. 3, lower right region). However, alloying the steels $14 Г 2 А \Phi$ and $16 Г 2 А Ф$ with vanadium in the amount of $0.1 \%$ and nitrogen in the amount of up to $0.016 \%$ increases their strength in comparison with ordinary steels.

Significant differences in the resulting areas of the contour plots in Fig. 3 are also caused by different chemical compositions of silicon and manganese. In the region with smaller values of $\mathrm{Z}^{\mathrm{Y}}$, the average content of $\mathrm{Si}$ and $\mathrm{Mn}$ is 0.37 $\%$ and $1.39 \%$, respectively, and for the higher $\mathrm{Z}^{\mathrm{Y}}$, the average content values are kept at the level of $0.9 \%$ for Si and $0.63 \%$ for Mn (Fig. 4).

Furthermore, it should be noted that manganese is an austenite-forming element and silicon a ferrite-forming element, and the phase composition of structural steels is affected as the concentrations of these elements increase. With an increase in the proportion of manganese in the matrix and a proportional decrease in the silicon content, the strength of steel increases, but so does the cost of metal products. On the other hand, the close relationship between the amount of carbon and the content of manganese indicates the need for a direct proportional increase.

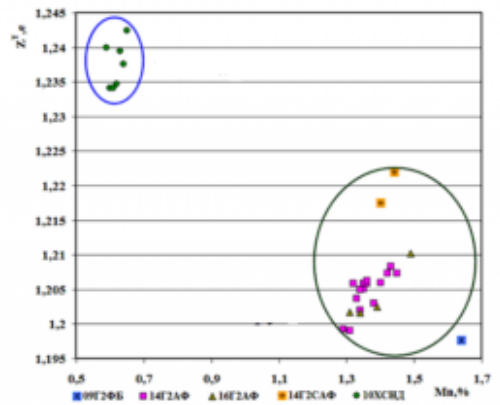

Fig. 4. Influence of manganese on the structural-charge state of structural steels.

The effect of manganese is a reduction in the tendency of steel to brittle fracture, which is observed in a number of structural steels with the carbon content of more than $1 \%$. This amount of carbon content is associated with an increase in the amount of the brittle carbide phase, which facilitates the crack initiation process.

\section{Conclusions}

Based on the analysis of a large sample of industrial data containing information about the chemical composition and mechanical properties of high-strength structural steels, a mathematical model with integral parameters of interatomic interaction has been developed. This model takes into account the contribution of the chemical composition and the cooling rate. In order to find the appropriate chemical composition resulting in the desired ranges for the tensile strength $\sigma_{\mathrm{B}}$ and elongation $\delta_{5}$, a multi-criteria optimisation technique was applied.

Integral parameters of interatomic interaction make it possible to assess, with high accuracy, the overall effect of the main alloying and microalloying elements $(\mathrm{Cr}, \mathrm{Ni}, \mathrm{V}, \mathrm{Mo}, \mathrm{Ti}, \mathrm{Nb})$ in a multicomponent metal system. It was demonstrated that the tensile strength can be increased by microalloying with chromium with an addition of nickel in the standard proportion. The alloying of structural steels with vanadium and a small amount of nitrogen increases their strength in 
Optimisation of chemical composition of high-strength structural steels for achieving m...

comparison with ordinary steels. Furthermore, it was also found that an increase in the manganese content increases the positive effect of the entire group of microalloying elements on the properties of this class of steels.

The advantage of the derived model is that through the dimension reduction of the parameter space (chemical composition) to a few integral parameters of the interatomic interaction, even the influence of new microalloying elements on the mechanical properties of steel can be reliably estimated in advance. Therefore, the proposed approach enables steel producers to reduce both energy and costs of carrying out additional experiments.

\section{Acknowledgements}

The authors gratefully acknowledge the financial support of the National Academy of Sciences of Ukraine within the project with reference KC.018.17.

\section{Bibliography}

[1] G. Buzzichelli, E. Anelli. Present Status and Perspectives of European Research in the Field of Advanced Structural Steels. ISIJ International. Volume 42, Issue 12, 2002, p. 1354 - 1363.

[2] X. Li, F. Li, Y. Cui, B. Xiao, X. Wang. The effect of manganese content on mechanical properties of high titanium microalloyed steels. Mater. Sci. Eng. A 667, 2016, p. 340-348.

[3] Qingshen Ma, Leqing Huang, Guobiao Dia, Yanfeng Wang, Yongda Yang, Changwen. Effect of microalloying elements on microstructure and properties of quenched and tempered constructional steel. IOP Conf. Series: Materials Science and Engineering 242, 2017, 012036 doi:10.1088/1757-899X/242/1/012036.

[4] I. Kalashnikov, O. Acselrad, A. Shalkevich, and L.C. Pereira. Chemical Composition Optimization for Austenitic Steels of the Fe-Mn-Al-C System. JMEPEG (ASM International), 9, 2000, p. 597-602

[5] G. Tregubenko. Improvement of the properties of low-alloy structural steels microalloyed with the "nitrogentitanium-aluminum" complex (in Russian). Металлургическая и горнорудная промышленность (Metallurgical and mining industry), 1, 2016, p. $67-71$.

[6] A. Babachenko, D. Togobitskaya, A. Kozachyok, A. Kononenko, A. Knysh, I. Snigur. Optimization of chemical composition of steel for railroad wheels providing stabilization of mechanical and increase of operational properties. Metallurgical and Mining Industry, No.3, 2017.

[7] E.C. Harrington. The desirability function. Industrial Quality Control, 21, 1965, p. 494-498.

[8] G. Derringer, R. Suich. Simultaneous optimization of several response variables. Journal of Quality Technology, 12, 1980, p. 214-219.

[9] J.R. Davis. High-Strength Low-Alloy Steels. Alloying: Understanding the Basics (ASM International), 2001.

[10] F. Schröter. Trends of using high-strength steel for heavy steel structures. Dillinger Hüttenwerke, Germany, 2006.

[11] V. Sorokin, M. Gervasjev. Steels and alloys. Intermet Engineering (in Russian), 2001

[12] A. Koltsov, E. V. Prikhod'ko, V. P. Vassiliev, V. Koltsov. The application of non-polarised ionic radii system for the description of physicochemical properties of solids, liquids and their interfaces. Materials Science, Current Opinion in Solid State \& Materials Science, 2005, doi:10.1016/J.COSSMS.2005.12.001 
[13] E. V. Prikhod'ko. Metal chemistry of multicomponent systems (in Russian). Металлургия, 1995.

[14] L.Ceschini A.Marconi C.Martini A.Morri A.Di Schino. Tensile and impact behaviour of a microalloyed medium carbon steel: Effect of the cooling condition and corresponding microstructure. Materials \& Design, Volume 45, March 2013, p.171-178.

[15] W. Bleck, D. Hömberg, U. Prahl, P. Suwanpinij, N. Togobytska. Optimal control of a cooling line for production of hot rolled dual phase steel. Steel research international 85 (9), 2014

PDF automatically generated on 2021-05-22 17:11:17

Article url: https://popups.uliege.be/esaform21/index.php?id=3654

published by ULiège Library in Open Access under the terms and conditions of the CC-BY License (https://creativecommons.org/licenses/by/4.0) 